\title{
An Unusual Combination of a MB2 Canal in a Maxillary Molar with a C Shaped Configuration and a Reverse S - Shaped External Root Contour Diagnosed with CBCT in a Maxillary Molar - A Case Report
}

\section{Lakshmi Aravind ${ }^{1 *}$, Siddharth V Nair ${ }^{1}$, Dilu Davis Chakkalakkal ${ }^{2}$, Lekshmy S Devi ${ }^{1}$ and Sreeja Sreedhar ${ }^{1}$}

${ }^{1}$ Department of Conservative Dentistry and Endodontics, Sri Sankara Dental

College, Kerala, India

${ }^{2}$ Department of Conservative Dentistry and Endodontics, PSM College of Dental Science and Research, Kerala, India

*Corresponding Author: Lakshmi Aravind, Department of Conservative Dentistry and Endodontics, Sri Sankara Dental College, Kerala, India.
Received: November 17, 2021

Published: December 13, 2021

(C) All rights are reserved by Lakshmi

Aravind., et al.

\begin{abstract}
The most predictable factor in endodontic treatment which results in a predictable outcome is if a clinician has any knowledge about the hidden internal anatomy of the root canal systems. Cone Beam Computed Tomography (CBCT) can act as the "third eye" for clinicians if they suspect any variability in canal configuration. This case report stresses the importance of such a preoperative CBCT evaluation, failure to do so results in a failed root canal treatment. The Palato - mesiobuccal canal of maxillary molars has been rightfully named so due to its close relationship to the palatal canal and can easily be mistaken for an additional palatal canal clinically. This case reports the rare occurrence of a combination of a C-shaped configuration in a Palato-MesioBuccal canal with a fluting of the root in a maxillary molar.
\end{abstract}

Keywords: C- Shaped Maxillary Molar; C-P-MB; Fluting; Palato-Mesiobuccal (P-MB)

\section{Abbreviations}

CBCT: Cone Beam Computed Tomography; P-MB: Palate- Mesiobuccal

\section{Introduction}

Maxillary molars show a myriad of anatomical variations [1]. The presence of additional canals in the mesial root canal system of maxillary molars has become the norm [2]. The usual location i.e., between a line joining mesiobuccal and palatal orifices, is where the clinician usually searches for the additional MB2 orifice [3]. This case report shows us via CBCT, the relatively rare location of the canal termed as P-MB (Palato- Mesiobuccal) combined with a C-shaped configuration as well as an unusual root contour with a fluting resembling a reverse $\mathrm{S}$ shaped outline [4].

\section{Case Report}

A 44-year-old male reported to the clinic with pain in his upper left back tooth. He gave a history of endodontic treatment in the same tooth around 6 months back and has had intermittent pain since then. Pain is present on mastication and the tooth was mildly tender on percussion. Clinical examination revealed a dislodged restoration in relation to maxillary left second molar. Pulp chamber showed GP sealed off at the orifice of the 3 main canals (MB, DB, P). A missed MB2 canal was suspected. Since the radiographic exami- 
nation did not reveal much regarding the presence of an additional canal, the patient was advised CBCT evaluation.

\section{CBCT analysis}

- $\quad$ Showed a root canal treated maxillary second molar with complete obturation of the 3 main canals (Figure 1)

- An additional P-MB canal in the mesiobuccal root near the palatal canal.

- $\quad$ The P-MB is seen to have a C-shaped configuration, hence termed C-P-MB (Figure 2).

- $\quad$ Fluting or a reverse S shaped contour seen on the external surface of the mesiobuccal root- (marked in red) (Figure 3).

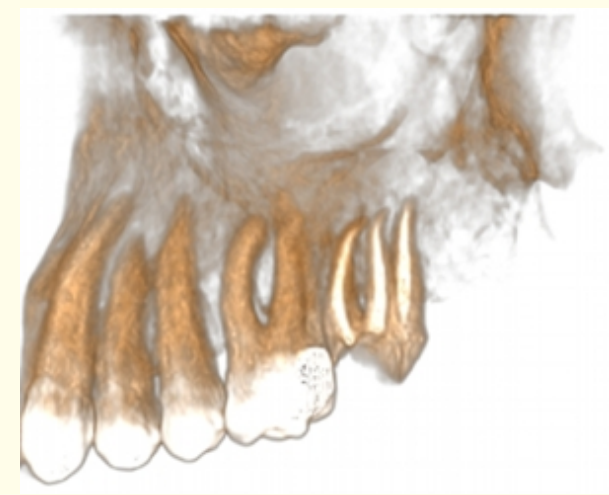

Figure 1: Shows a root canal treated maxillary second molar with complete obturation of the 3 main canals.

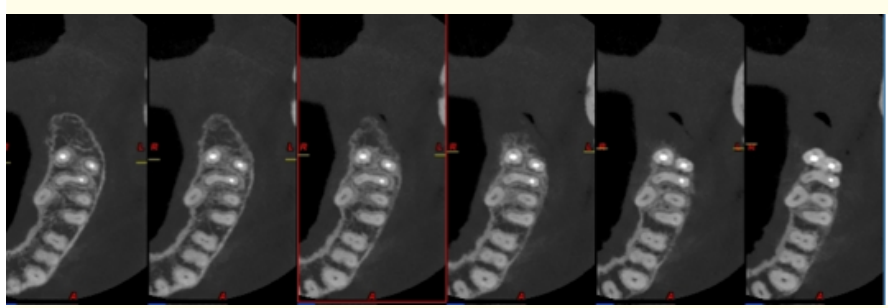

Figure 2: Shows an additional P-MB canal in the mesiobuccal root near the palatal canal. The P-MB is seen to have a C-shaped configuration, hence termed C-P-MB.

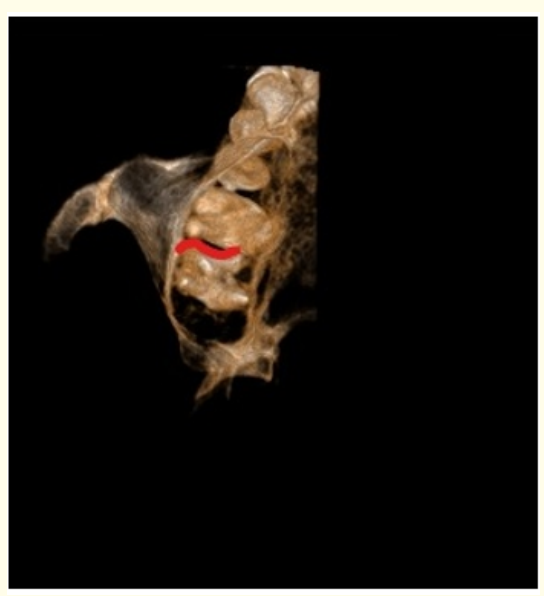

Figure 3: Fluting or a reverse $S$ shaped contour seen on the external surface of the mesiobuccal root- (marked in red).

\section{Discussion}

The MB2 is usually located closer to the mesiobuccal canal in most of the cases [5]. The P-MB has been documented only a few times in the literature [6-8]. The C-shaped configuration and P-MB configuration has been has rarely, if ever reported. The reverse $\mathrm{S}$ shaped contour and fluting of the root is an important factor to be considered, as a blind searching of MB2 in this usual location may result in a perforation. Judicious use of pre-operative CBCT analysis and Dental operating microscope are of great advantage in such cases. Minimal preparation without excess dentin removal is also warranted due to the external anatomy of the root. CBCT was a useful addition in this case especially as blind troughing and gouging could be avoided in the search for the MB2 canal in its usual location which might have resulted in excessive thinning or a perforation in the area. The morphology of the mesiobuccal root of the maxillary molars is very complex the various anatomic configurations including a $\mathrm{C}$ - shaped canal has not been properly classified in literature.

\section{Conclusion}

Hence, it is imperative for the clinician to be aware of such rare root morphologies and canal configurations to avoid unnecessary complications later during the treatment. 


\section{Bibliography}

1. Barbizam JV., et al. "Unusual anatomy of permanent maxillary molars". The Journal of Endodontics 30 (2004): 668-671.

2. Peikoff MD., et al. "The maxillary second molar: variations in the number of roots and canals". International Endodontic Journal 29 (1996): 365-369.

3. Kulild JC., et al. "Incidence and configuration of canal systems in the mesiobuccal root of maxillary first and second molars". The Journal of Endodontics 16 (1990): 311-317.

4. Kottoor Jojo., et al. "A New Anatomically Based Nomenclature for the Roots and Root Canals-Part 1: Maxillary Molars". International Journal of Dentistry (2012).

5. Frank J., et al. "Tooth morphology and Access cavity preparation". In: Cohen S, Burns RC, editors. Pathways of the Pulp. 10th ed. St. Louis: Mosby Yearbook (2010): 136-222.

6. Kanyal K., et al. "Unusual location of second mesiobuccal orifice in maxillary second molar". Endodontology 28: (2016): $57-$ 59.

7. Chakradhar Raju RV., et al. "Endodontic management of a maxillary first molar with unusual location of second mesio buccal orifice". Journal of Conservative Dentistry 13 (2010): 162-164.

8. Randhya R., et al. "Unusual Location of a Second Mesiobuccal Canal in the Maxillary First Molar managed with the Aid of Cone-beam Computed Tomography". Journal of Operative Dentistry and Endodontics 1 (2016): 35-38.

\section{Assets from publication with us}

- Prompt Acknowledgement after receiving the article

- Thorough Double blinded peer review

- Rapid Publication

- Issue of Publication Certificate

- High visibility of your Published work

Website: www.actascientific.com/

Submit Article: www.actascientific.com/submission.php

Email us: editor@actascientific.com

Contact us: +919182824667

Citation: Lakshmi Aravind., et al. "An Unusual Combination of a MB2 Canal in a Maxillary Molar with a C Shaped Configuration and a Reverse S - Shaped External Root Contour Diagnosed with CBCT in a Maxillary Molar - A Case Report". Acta Scientific Dental Sciences 6.1 (2022): $42-44$. 